\title{
The differential effects of two vocabulary instruction methods on EFL word learning: A study into task effectiveness
}

\author{
ELKE PETERS
}

\begin{abstract}
This study examines the effect of two vocabulary instruction treatments on word retention by 56 EFL learners. In particular, it focuses on the differential effects of a message-oriented treatment (reading text and answering comprehension questions) and a vocabulary-oriented treatment (reading text and performing two vocabulary tasks) on learners' recall and recognition of the meaning of 14 target words. Learners in the two groups were required to first read a text, in which they encountered the 14 target words for the first time, before carrying out their respective task. Both groups were required to process and actually use the target words when carrying out their task. Finally, both groups were allotted the same amount of time to complete their task. The results of immediate and delayed vocabulary post-tests indicate that the vocabulary-oriented treatment yielded greater vocabulary learning gains than the message-oriented treatment.
\end{abstract}

\section{Introduction}

There is general consensus among researchers in the field of instructed second language acquisition (SLA) that reading as an instructional method is not the most efficient way to foster vocabulary acquisition. Though reading activities certainly have the potential to increase learners' vocabulary size, these vocabulary gains tend to be small and unpredictable (Horst, Cobb, and Meara 1998; Hulstijn, Hollander, and Greidanus 1996; Laufer 2005; Nation 2001; Schmitt 2008). This low incidence of vocabulary acquisition through reading can be boosted by tasks or techniques that prompt L2 learners to find the meaning of unfamiliar words and make them process their lexical information elaborately (Peters, Hulstijn, Sercu, and Lutjeharms 2009). One can distinguish between text comprehension activities (= text message-oriented activities) and vocab- 
ulary tasks (= vocabulary-oriented activities). Empirical studies have shown that L2 learners benefit from message-oriented tasks that prompt them to look up and process target words when answering comprehension questions (Peters 2007; Peters et al. 2009). On the other hand, post-reading vocabulary activities promote vocabulary acquisition as well (Hill and Laufer 2003; Hulstijn and Laufer 2001; Laufer 2006; Paribakht and Wesche 1997, 1998; Peters et al. 2009). It remains, however, unclear whether one is more effective than the other because the tasks used were different in several respects (with/without reading text, differences in time-on-task, L1-L2 versus L2-L1 tasks). Therefore, this study was set up to advance our understanding of the effect of different vocabulary instruction treatments on word retention by using a more tightly controlled research design. In particular, this study set out to explore how two text-related vocabulary instruction treatments, a message-oriented (text comprehension task) and a vocabulary-oriented (vocabulary tasks) treatment, affect word learning by EFL learners.

\section{Background}

Over the last 15 years, the field of instructed second language acquisition has witnessed a growing interest in how pedagogic tasks can facilitate second and foreign language acquisition (see for instance Ellis 2003; Garcia-Mayo 2006; Van den Branden 2006; Van den Branden, Bygate and Norris 2009).

The theoretical underpinnings of most vocabulary studies and of the studies reviewed in this section are based on the assumption that vocabulary acquisition is fostered by tasks or techniques that make L2 learners allocate attentional resources to unfamiliar words, for instance by finding the meaning (Chun and Plass 1996; De Ridder 2002; Hulstijn et al. 1996; Laufer and Hill 2000; Peters 2007), and process their lexical information elaborately to establish a formmeaning connection of the word-to-be-learned (Hulstijn 2001; Schmitt 2008). The "Levels-of-Processing" theory (Craik and Lockhart 1972; Craik and Tulving 1975) states that retention of information is strongly determined by the way the information is processed. A more recent attempt to measure the depth-ofprocessing of words is the Involvement Load Hypothesis, proposed by Laufer and Hulstijn (2001). This framework for research on L2 word learning consists of one motivational component, Need (the need to accomplish a task) and two cognitive components, Search (the attempt to find the meaning of a word or the word form for a concept), and Evaluation (comparison of a meaning or word form with other meanings or word forms). Laufer and Hulstijn postulated that retention of new words is contingent upon the degree of involvement in processing these words (p. 545). 
Laufer $(2005,2006)$ proposes form-focused vocabulary instruction in addition to reading. Following Long's terminology $(1991)^{1}$, she distinguishes between Focus on Form (FonF) and Focus on FormS (FonFs) vocabulary activities. The former refers to lexical items within a communicative task environment because the lexical items are necessary for the completion of a task, whereas the latter (FonFs) refers to the teaching and practising of discrete lexical items in non-communicative language tasks. An example of FonF would be L2 learners' attention to marginal glosses to answer comprehension questions. A typical example of FonFs would be list learning (for studies on list-learning, see Mondria 2003; Mondria and Wiersma 2004; Steinel, Hulstijn, and Steinel 2007).

Another strand of research has dealt with the effect of text-related tasks that require learners to use unfamiliar words in one way or another. In this respect, text comprehension activities (= text message-oriented activities) can be distinguished from vocabulary tasks (= vocabulary-oriented activities). Because these studies are of special interest to the present paper, they are discussed in more detail in the following subsections.

\subsection{Message-oriented activities}

In a computer-based study, conducted by Peters (2007), the effect of Taskinduced Word Relevance on learners' look-up behavior and their retention of 16 words was investigated. Half of the target words were relevant to perform a text comprehension task (= relevant target words), the other half was not (= non-relevant target words). The concept of Word Relevance is in line with what Loschky and Bley-Vroman (1993) call task-essentialness, i.e., the task cannot be accomplished successfully unless the targeted structures, the relevant target words in this case, are used. Participants (L1 = Dutch) read a German text, containing the target words, on a computer screen. They could look up words in an online dictionary. The comprehension questions were developed in such a way that the relevant target words' meaning had to be incorporated in the answer to the accompanying question. The non-relevant target words were not related to the comprehension questions. Unlike some other studies (Hulstijn and Laufer 2001; Hill and Laufer 2003), in which multiple choice or yes/noquestions were employed, learners were not solely required to grasp the target words' meaning but also to use the words in their answer to the questions. The findings showed that participants looked up more relevant than non-relevant

1. Long (1991) first coined the labels FonF and FonFs. FonF refers to drawing attention to linguistic features while the main focus in on meaning and communication. FonFs, on the other hand, refers to teaching linguistic features as discrete items, e.g., plural form. 
target words (= Need and Search dimension of Involvement Load Hypothesis) and that they recalled the meaning of more relevant target words than of nonrelevant ones. Findings were explained in light of processing theories and the Involvement Load Hypothesis. Yet, the question that needs to be addressed now is whether a post-reading vocabulary task would have a similar or an even better effect.

\subsection{Vocabulary-oriented activities}

Most studies in this area have compared the effect of vocabulary tasks with text comprehension activities. Paribakht and Wesche $(1997,1998)$ explored the effect of a Reading Only treatment and a Reading Plus treatment. The former involved multiple exposures to target words via reading texts, whereas the latter focused on reading a text followed by text-related vocabulary tasks. Both treatments required approximately the same amount of class time. Paribakht and Wesche found that the Reading Plus treatment resulted in higher learning gains than the Reading Only treatment. But, unlike the Reading Plus treatment, the Reading Only treatment did not require learners to actually use the target words.

Empirical evidence for the Involvement Load Hypothesis was provided in a study by Hulstijn and Laufer (2001), in which three tasks were compared. In task 1, learners read an English L2 text with marginal glosses and they answered multiple choice comprehension questions. Learners were required to understand the target words' meaning but not to use them, when answering the comprehension questions. This task took approximately 40 to 45 minutes. Task 2 was identical to the first one, except that the target words were deleted from the text. In addition to answering comprehension questions, learners had to fill in the gaps with a target word selected from a list of words with their meaning. This task took about 50 to 55 minutes. Learners who carried out task 3 wrote a composition in which they had to use the target words. This group was provided with the meaning of the words and an example of their usage, but not with the text. Because the last task was also the most demanding one, it is no surprise that it took 70 to 80 minutes to be completed. Word retention was best in the third group. However, this group worked much longer than the other groups and almost twice as long as the first group. Though Hulstijn and Laufer consider the time-on-task an inherent characteristic of the task (p.549), the better learning performance of the third group may be attributed to the time learners spent on the task.

Time-on-task was specifically taken into account in a computer-based study by Hill and Laufer (2003). Learners were assigned to one of three tasks: a message-oriented task, a form-oriented comprehension task, and a form- 
oriented production task. Time-on-task was registered in all three groups to ensure that an effect could only be attributed to the task and not to the time spent on the task. Task 1 (the message-oriented task) consisted of an online text, and yes/no comprehension questions. Like the study by Hulstijn and Laufer (2001), learners had to understand the meaning of the target words to answer the questions but they did not have to use them. Participants who performed task 2 (the form-oriented comprehension task) were provided with the same text. Instead of answering comprehension questions, they completed a vocabulary task, in which they had to tick off the correct meaning of the target words. Participants who were assigned to task 3 were given the text together with a list of words accompanied by their definition. They had to select the correct word form for a given meaning (= form-oriented production task). The findings showed that the form-oriented production task yielded the highest scores in the immediate post-test. However, there was no significant difference in retention between the form-oriented comprehension and production task. On the delayed test, there was only a significant difference between learners assigned to task 1 and learners assigned to task 3 .

Laufer (2006) $)^{2}$ compared the effect of a FonF and a FonFs vocabulary task on word retention by 158 ESL learners. Participants assigned to the FonF task read an L2 text containing the target words and performed a comprehension task. Answering the comprehension questions required the understanding of the target words. Participants assigned to the FonFs task were given a list of target words with their translation and L2 explanations. They had to perform two word-focused tasks. Time-on-task was identical for both groups. Learners who had completed the vocabulary tasks recalled the meaning of more target words than learners who had performed the reading comprehension task.

In another study, Laufer and Rozovski-Roitblat (2011) compared the effect of frequency of occurrence in a FonF and in a FonFs-setting. Their findings showed that EFL learners fared better when they had practised the words during vocabulary-focused or FonFs activities compared to encountering these items, as often or even more often, during reading/FonF activities.

To sum up, the research findings presented in this subsection point to the superiority of vocabulary-oriented activities over message-oriented activities (= text comprehension tasks). But a short comment on these findings is warranted because there were quite some differences between the tasks used. First, some groups were given a reading text, others were not, as was the case in the Hulstijn and Laufer study (2001) and the study by Laufer (2006). Unlike the vocabulary-oriented tasks, the message-oriented tasks did not require the learners to actually do something with the target words (Paribakht and Wesche

2. Only Part 1 of the Laufer (2006) study is discussed. 
1997, 1998), although their meaning was sometimes relevant to the comprehension questions (Hulstijn and Laufer; Laufer 2003, 2006). In addition, some studies compared L2-L1 tasks with L1-L2 tasks (Laufer 2003). Finally, timeon-task was not identical in all studies (Hulstijn and Laufer 2001). Hence, it is not straightforward to compare the effect of these tasks on word retention. The present study wants to address this issue and examine what the effect on word retention is when the aforementioned factors are kept constant for two vocabulary instruction treatments.

\subsection{Message-oriented activities followed by a vocabulary-oriented activity}

Peters and colleagues (2009) examined the effect of Task-Induced Word Relevance (= operationalized via a text comprehension task), a vocabulary task and the interaction among them on learners' look-up behavior and their word retention. Participants were randomly assigned to either the Input Only group (text comprehension task, no vocabulary task) or the Input Plus group (text comprehension task and vocabulary task). All participants ( $\mathrm{L} 1=$ Dutch) read a German text, containing the target words, on a computer screen and performed a text comprehension task that was identical to the one used in Peters (2007). They could look up unknown words in an online dictionary. To successfully complete the comprehension task, learners needed to look up, process and incorporate the meaning of half of the target words (= relevant target words) in their answer to the comprehension questions. Thus, half of the target words were relevant to accomplish the text comprehension task (= relevant target words), the other half was not related to the comprehension questions (= non-relevant target words). In addition to the text comprehension task, participants in the Input Plus group also carried out a post-reading vocabulary task, in which all target words, relevant as well as non-relevant ones, were presented again. Learners had to provide an L1 translation or an L2 synonym for the target words. The findings showed that Word Relevance affected 1) learners' willingness to look up and process the meaning of unknown (relevant) words and 2) their retention of these words. In addition, the group that had carried out a post-reading vocabulary task (= Input Plus group) performed better than the Input Only group on the immediate as well as delayed post-tests since they were prompted to process the target words while reading the text and answering the comprehension questions and to process them again in the post-reading vocabulary task. Especially the interaction between Word Relevance and the vocabulary task promoted word retention.

Interestingly, there were differences in vocabulary loss between the two groups and the two categories of target words. The learners who had carried out a vocabulary task, in which all target words were presented, after 
the comprehension task (= Input Plus group) forgot more non-relevant target words (= non-relevant in terms of answering the comprehension questions) than the learners in the Input Only group (= comprehension task but no postreading vocabulary task) forgot relevant target words. This may imply that words used only in a text comprehension task are processed differently than words used only in a vocabulary task. In other words, this may mean that a text meaning-oriented, comprehension task is more beneficial for word learning than vocabulary-oriented tasks. However, this interpretation remains speculative because the study by Peters et al. was not specifically designed to compare these two types of tasks. The present study aims to unravel this issue.

\section{Aim and research questions}

The studies reviewed above show that tasks that prompt learners to process and use words either in a text comprehension task or in a vocabulary task result in better word retention than tasks that do not. However, because the research design of the aforementioned studies differed in several respects, the question whether one is more beneficial for word retention than the other has been insufficiently answered. This study aims to explore the effect of a text comprehension and vocabulary task on retention of target words by employing a more controlled research design. It differs from the aforementioned studies by combining the following factors in one experimental design:

- all participants read a text, in which they encounter the target words for the first time,

- the two treatments under investigation require learners to look up and process the meaning of the target words,

- the two treatments are allotted the same amount of time. In this respect, it is also a study into task-effectiveness.

Both tasks are text-related and require L2 learners' attention to the target words, but whereas the text comprehension task is text message-oriented, the other task is (explicitly) vocabulary-oriented. Hence, I adopt the labels messageoriented treatment for the comprehension task and vocabulary-oriented treatment for the vocabulary task in the remainder of the paper.

This research wants to find an answer to the question which vocabulary instruction treatment is more beneficial for immediate and delayed word retention, (1) as measured in a recall test, and (2) as measured in a recognition test, when the same amount of time is allotted to the two treatments. 


\section{Method}

\subsection{Participants}

The participants in this study were 60 EFL learners (17 male, 43 female) from one intact class, who were studying English Translation and Interpreting studies at a Flemish university college. They were considered advanced students, which was also corroborated by the results of a vocabulary size test (see Results section). All students had Dutch as their L1; two students were bilingual (Dutch-French). The data of four participants were removed from the data analysis because they were not present during the last session, when the delayed post-tests were administered. This brought the total number of participants to 56 (17 male, 39 female).

\subsection{Design}

The study adopted a $2 \times 2$ design with one between-subject variable, Vocabulary Instruction Treatment (message- or vocabulary-oriented) and one withinsubject variable, Time (word retention, immediately and two weeks after the experimental task). Thus, the design consisted of two experimental groups (see Table 1). Group 1 is labeled "Message-oriented group" and Group 2 "Vocabulary-oriented group".

Participants in the two groups read an L2 text with marginal glosses and they each carried out a text-related, yet different task. The study adopts the definition of "task" provided by Richards, Platt, and Weber (1985), who define a task as "an activity or action which is carried out as the result of processing or understanding language" (1985: 289). Obviously, this definition does not conform to the definition of a task in a task-based approach. ${ }^{3}$ The two groups were allotted the same amount of time ( 35 minutes); they had the glossed text at their disposal when performing the tasks. Participants were randomly assigned to either the message-oriented or the vocabulary-oriented treatment.

The message-oriented treatment consisted of a text comprehension task comprising ten questions. The target words appeared in text passages whose content was targeted by the comprehension questions. Thus, the target words were relevant to the text comprehension task, which could not be performed successfully unless the target words were integrated in the answer to the accompanying

3. Skehan (1998: 95) argues that a task (in a task-based approach) must meet five criteria. In a task, meaning is primary. There is some communication problem to solve. The task bears resemblance to real-word activities. Task completion has some priority. Finally, the assessment of the task is in terms of outcome (see also Ellis 2003). 
Table 1. Research design

\begin{tabular}{lll}
\hline & $N$ & Type of Treatment \\
\hline Group 1 & 29 & Message-oriented \\
Group 2 & 27 & Vocabulary-oriented \\
\hline
\end{tabular}

question. To ensure that the participants would not just copy the relevant sentence or text passage and that they would process the meaning of the target words, they had to answer in their L1, Dutch. For this reason, questions were also phrased in Dutch.

The vocabulary-oriented treatment consisted of two vocabulary tasks, in each of which the 14 target words were presented once. In contrast to the message-oriented group, the vocabulary-oriented group had to complete two tasks to ensure that the time-on-task would be identical. In the first vocabulary task, participants were provided with sentences taken from the text and which contained at least one of the target words. The learners were asked to translate the target word into their L1, Dutch. In the second task, a multiple choice task, participants had to tick off the correct L2 meaning of the target word. The experimental tasks and the time-on-task of the two treatments had been piloted to guarantee that the learning tasks and their instructions would be clear. The pilot showed that 35 minutes would suffice to complete the tasks and that the time-on-task was equal for the two groups.

Word retention constituted the dependent variable. It was measured immediately as well as two weeks after the experimental task to investigate whether word retention had changed over time.

\subsection{Materials}

4.3.1. Target words. The target words were taken from the text students had to read and were selected after all participants were pre-tested on their knowledge of the target words' meaning.

Two weeks prior to the experimental treatment, a written pre-test was administered to all participants to ensure that the target words were indeed unknown. The test contained 48 (English) test items. Most items were taken from the reading text, the others were (near)-synonyms of words in the text or distractors. The items that were taken from the reading text were first checked against the learners' vocabulary text books to ensure that they would not have been studied yet. Second, the frequency of the test items was verified in the Collins 
Cobuild Dictionary. ${ }^{4}$ Only test items from the two lowest frequency bands were retained. In the selection procedure, a representation of nouns, verbs and adjectives was aimed at. The participants were asked to provide a Dutch translation or an English synonym for the 48 test items.

On the basis of the test results, 14 target words that were unknown to all participants were selected: adversity, bauble, foible, paean, trappings, to aggrieve, to purloin, to slaver, to suffuse, to venerate, bouffant, gauche, hapless and tawdry (five nouns, five verbs, and four adjectives). Each target word appeared in the text only once. Five of these target words were initially not in the text. Their meaning, however, was similar to the meaning of the words that occurred originally in the text. Thus, five words that were initially in the text were replaced with less-frequent (near)-synonyms (e.g. "unlucky in love" was replaced with "hapless in love"; "weaknesses" with "foibles"). These lessfrequent target words were part of the pre-test and appeared to be unknown to the participants compared to the original words in the text. It was verified with a native speaker that these five target words all fit the context.

4.3.2. Text. Participants had to read a slightly adapted 952-word text selected from a British newspaper. It dealt with the fascination of the British people with the phenomenon of fame and celebrity. Forty-one words, including the 14 target words, were underlined and glossed in the margin (L1 translation).

\subsubsection{Text comprehension task. The text comprehension task consisted of} ten factual comprehension questions in learners' L1, Dutch, which learners had to answer with the text and the marginal glosses at their disposal (see Fig. 1).

The questions were of the so-called "textually explicit" type, meaning that the question-answering process "involves search-and-match strategies rather than actual comprehension" (Alderson 2000: 107). The target words were essential to complete the task successfully since the participants needed to understand, process and incorporate the Dutch translation of the target words in their answer to the comprehension questions. The questions (in Dutch) had to be answered in learners' L1, Dutch, to ensure that the learners would consult the marginal glosses and would use the translation of the target words (= target word's meaning) in their answer. Otherwise, the participants could copy the sentences without processing the target words' meaning. Note that a correct answer to the comprehension question requires that the learners integrate the

4. The Collins Cobuild English Dictionary (Sinclair 2001) divides the words listed into five frequency bands, indicated by diamonds, with a maximum of five diamonds. The most frequent words are given five diamonds (approximately 680 words). The fewer diamonds, the less frequent the words are. Some words, which do not have a diamond, are the least frequent ones. 
Text excerpt (target word adversity is underlined):

We like to imagine that celebrity on this scale is a modern phenomenon, but it is not. It is a story compounded of glamour, failed romance, personal adversity and lots of pretty frocks, and it is one repeated, with only minor variations, in our history

Text comprehension question pertaining to this passage:

Beroemdheid is geen typisch modern fenomeen. Het is een oud verhaal. Maar waaruit bestaat het precies? Geef de vier elementen: (Celebrity is not a typically modern phenomenon. It is an old story. But what does it consist of? Give the four elements of which it consists.)

Answer to this question (target word is underlined):

Het bestaat uit glamour, mislukte romances, persoonlijke tegenslagen en veel mooie jurken. (It consists of glamour, failed romance, personal adversity and lots of pretty frocks).

Figure 1. Example of a text comprehension question

target word's meaning in a proposal meaningfully connected to the question (= processing lexical information of new words). In other words, an answer to a question was only considered correct when it contained the target word's meaning that pertained to the accompanying question. For instance, for the question in Figure 1, learners had to understand the meaning of the target word adversity, process it and integrate it in their answer. Four questions required the understanding and use of two target words. Thus, for all comprehension questions, the participants needed to find the meaning of the target word(s), process it and integrate it in their answer. Following Laufer (2005), this task would constitute a FonF-vocabulary task.

4.3.4. Vocabulary tasks. As already mentioned in the Design section, the vocabulary-oriented treatment consisted of two vocabulary tasks (see Figure 2). The first task was a translation task. Learners were provided with ten sentences taken from the text verbatim. In each sentence, they had to translate a word or phrase. ${ }^{5}$ As can be seen in Figure 2, learners had to supply an L1 trans-

5. As one reviewer suggested, this task may look similar to the comprehension task because both tasks require participants to supply an answer in their L1. However, it needs to be stressed that the two tasks are not identical. Whereas the comprehension task required the messageoriented group to first find the answer to the comprehension question in the text and then to give an answer in their L1, the vocabulary-oriented group had to supply the L1 translation for the target word that was presented in a sentence taken from the text verbatim. They could go 


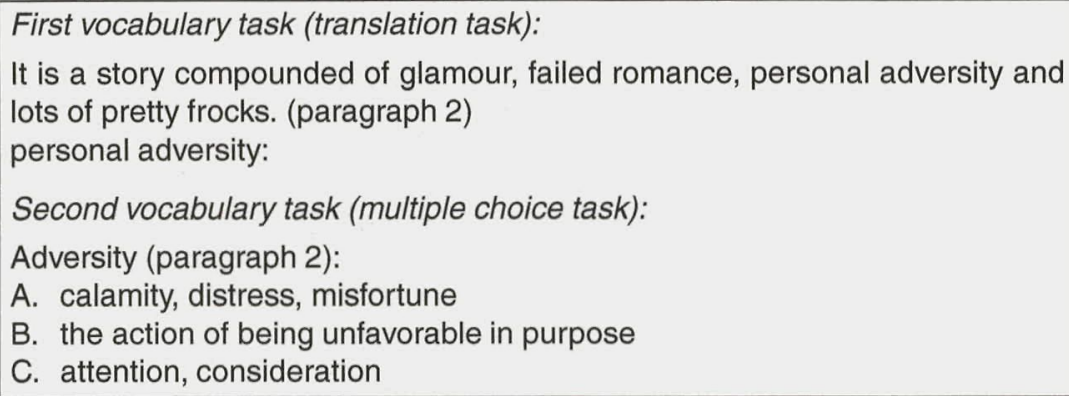

Figure 2. Example of target word "adversity" offered in translation and multiple-choice task

lation for personal adversity. Six sentences contained one target word each; four sentences two target words each. The second vocabulary task was a multiple choice task comprising 14 items. The learners had to recognize the L2 meaning of the target word among three options (see Figure 2 for an example). The text (with marginal glosses) remained available (in Laufer's (2005) terminology, these tasks could be considered FonFs-vocabulary tasks). As already mentioned, all tasks were piloted to make sure that the learning tasks and their instructions would be clear.

\subsection{Data collection instruments}

The data collection instruments consisted of two vocabulary post-tests, the Vocabulary Levels Test (Nation 2001), and three retrospective questions.

4.4.1. Vocabulary post-tests. Retention of the target words' meaning was tested in two vocabulary post-tests to detect possible, qualitative differences relating to the type of vocabulary knowledge: a recall and a recognition posttest. In a recall test, learners need to retrieve the meaning or form of a word from their memory, whereas in a recognition test, they need to recognize the meaning or word form among several options. Recognition tests are said to be easier than recall tests (Nation 2001).

The meaning recall test presented the 14 target words in isolation; so no context was provided. Learners were required to supply an L1 translation or an L2 synonym/definition. For example:

back to the text to find the target word's meaning in the marginal glosses but they did not have to go looking for an appropriate answer with regard to the content of the text. 
to suffuse:

hapless:

In the meaning recognition test, learners had to match the target words with their correct meaning. The options from which participants could choose were offered in their L1, Dutch, to minimize the task-test similarity for the participants in the vocabulary-oriented group. If the multiple choice options had been in English, this group would have been at an advantage because of the exact similarity between the second vocabulary task (the multiple choice task) and the recognition test. The target words were clustered in three groups on the basis of word class: noun, verb, and adjective. For the five nouns and the five verbs, seven options were provided to minimize the chance of successful guesses (see example below); for the four adjectives six options were offered. These two vocabulary post-tests were administered immediately after the experimental task and two weeks later (see also procedure). For example:

$\begin{array}{llll} & & \text { a. } & \text { sier, versiersel } \\ \text { 1. } & \text { adversity } & \text { b. } & \text { zwakheid, tekortkoming } \\ \text { 2. trappings } & \text { c. } & \text { tegenslag, ongeluk } \\ \text { 3. bauble } & \text { d. lofzang, triomflied } \\ \text { 4. foible } & \text { e. vleug, zweem van } \\ \text { 5. paean } & \text { f. edelsteen, juweel } \\ & & \text { g. } & \text { pracht, praal }\end{array}$

4.4.2. Vocabulary size test. To get an estimate of learners' vocabulary size, the Vocabulary Levels Test was administered (Nation 2001). This test, a recognition test, contains test items from different frequency levels: 2,000, 3,000, $5,000,10,000$ word level and the Academic Word List (AWL). The test is divided into five subtests, which correspond to the aforementioned frequency levels. In each subtest, test takers need to match 30 test items with the correct meaning. Because the participants in this study were considered advanced EFL students, only the subtests related to the 5000-word level, the AWL, and the 10,000 word level were administered. The results of this test were used to check whether there were any differences in vocabulary size between the two groups.

4.4.3. Three retrospective questions. On completion of the vocabulary posttests, the participants answered three retrospective questions.

1. Had you expected the vocabulary post-tests?

2. Do you think that the task you were set was a good preparation for the vocabulary post-tests?

3. Did you find the task motivating? 
These qualitative data were used to interpret the test results.

\subsection{Procedure}

The experimental procedure consisted of three sessions. During the first session, participants took the written pre-test to ensure that no one knew the target words. On the basis of the test results, the 14 target words were selected. Four weeks later, the participants performed the actual experimental task. They were randomly assigned to either the message-oriented or the vocabulary-oriented group. All participants received the learning instruction, the reading text, and their respective task on paper. They started by reading the learning instruction pertaining to their specific task. All participants were told that they had 35 minutes to read a text with marginal glosses and to perform a task. Participants in the message-oriented group were informed that they first had to read a text for general comprehension before starting to answer text comprehension questions with the reading text and its marginal glosses at their disposal, whereas the vocabulary-oriented group was told that they first had to read a text for general comprehension before starting to carry out two vocabulary tasks with the glossed text being available. The learning instruction did not mention that the aim of the experiment was vocabulary learning; no reference was made to the vocabulary post-tests. Next, participants started reading the text and performing the tasks. Students had the opportunity to ask questions in case anything (instruction or distractors used in the vocabulary task) was not clear, but no one did. Both groups were able to complete their task within the allotted 35 minutes. Nevertheless, all participants were asked to write down the time when they had finished their task. Immediately after handing in their tasks, all participants took the two unexpected vocabulary post-tests, first the recall test and then the recognition test. The second session ended with a short questionnaire, in which participants had to answer the three retrospective questions about how they had experienced and perceived the learning task(s). During the third session, which was organized two weeks later, all participants took the same recall and recognition test without any warning, but the test items were presented in a different order to control for any order effects. Next, they took three subtests of the Vocabulary Levels Test (5,000 and 10,000 word level, AWL). At the end, participants were debriefed about the aim of the experiment. The experiment took place during students' class hours.

\subsection{Data analysis}

The vocabulary tasks were scored dichotomously. The comprehension task was marked as follows: a fully correct answer received a score of one; a partially 
correct answer a score of 0.5 (target word was used but the answer was incomplete); a wrong answer a score of 0 (which implied that the target word was not used; see also the Design section). ${ }^{6}$

The vocabulary post-tests were scored dichotomously. A correct answer received a score of one, an incorrect one a score of zero (no translation or a wrong translation). All tests and tasks were scored by the researcher. The test scores were submitted to a $2 \times 2$ ANOVA with Type of Treatment (vocabularyoriented or message-oriented) as between-subject variable and Time (immediate and delayed post-tests) as within-subject variable to determine whether the independent variables had a significant effect on word learning. A p-level of .05 was set. As a measure of effect size, eta-squared $\left(=\eta^{2}\right)$ was chosen. ${ }^{7}$

\section{Results}

First, the descriptive statistics of the tasks and the vocabulary size test are provided before learners' performance on the vocabulary post-tests is discussed. The Result section ends with the analysis of the retrospective questions.

\subsection{Task results}

The mean scores of the tasks show that the vocabulary-oriented group performed better than the message-oriented group on the tasks they had to carry out (see Table 2). In addition, they needed fewer minutes compared to the message-oriented group, though it needs to be emphasized that it was only a rough estimate of the time-on-task because learners wrote down the time themselves upon completing their task. Nevertheless, it was possible to discover possible, large discrepancies.

\subsection{Learners'vocabulary size}

As can be seen in Table 3, all learners performed excellently on the subtests of the 5,000 words level and the AWL.

Scores were lower on the 10,000 words level. Although the two groups did not differ in their average score on the 10,000 words subtest, there was more

6. Four questions required the understanding and use of two target words. These questions had a maximum score of 2 instead of 1 .

7. The values of effect size were interpreted as follows: $\eta^{2}>.0099$ (small), $\eta^{2}>.0588$ (moderate), and $\eta^{2}>.1379$ (large) (Cohen 1992). For instance, an eta squared with a value of .40 would indicate that the effect size is large. 
Table 2. Descriptive statistics of task scores (Max. =14) and time-on-task

\begin{tabular}{|c|c|c|c|c|c|c|}
\hline \multirow[t]{2}{*}{ Treatment } & \multirow[t]{2}{*}{ Task } & \multirow[t]{2}{*}{$\mathrm{N}$} & \multicolumn{2}{|c|}{ Score } & \multicolumn{2}{|c|}{ Time } \\
\hline & & & Mean & $\mathrm{SD}$ & Mean & SD \\
\hline $\begin{array}{l}\text { Message-oriented treat- } \\
\text { ment: }\end{array}$ & comprehension task & 29 & 10.8 & 1.8 & 30.7 & 3.3 \\
\hline \multirow{2}{*}{$\begin{array}{l}\text { Vocabulary-oriented treat- } \\
\text { ment: }\end{array}$} & translation task & 27 & 13.1 & 1.3 & 26.7 & 3.6 \\
\hline & multiple choice task & 27 & 13.2 & 1.0 & & \\
\hline
\end{tabular}

Table 3. Descriptive statistics of vocabulary size test

\begin{tabular}{|c|c|c|c|c|c|c|c|c|c|}
\hline & \multirow[b]{2}{*}{$\mathrm{N}$} & \multicolumn{2}{|c|}{$\begin{array}{c}5,000 \text {-level } \\
\mathrm{Max}=30\end{array}$} & \multicolumn{2}{|c|}{$\begin{array}{c}\text { AWL } \\
\operatorname{Max}=30 \\
\end{array}$} & \multicolumn{2}{|c|}{$\begin{array}{c}10,000 \text {-level } \\
\text { Max }=30 \\
\end{array}$} & \multicolumn{2}{|c|}{$\begin{array}{l}\text { Total score } \\
\text { Max }=90\end{array}$} \\
\hline & & mean & $\mathrm{SD}$ & mean & SD & mean & SD & mean & SD \\
\hline Message-oriented group & 29 & 28.3 & 2.0 & 29.0 & 1.4 & 22.0 & 4.3 & 79.3 & 6.8 \\
\hline Vocabulary-oriented group & 27 & 28.3 & 2.2 & 29.2 & 0.9 & 22.0 & 5.3 & 79.6 & 7.2 \\
\hline All learners & 56 & 28.3 & 2.1 & 29.1 & 1.2 & 22.0 & 4.8 & 79.4 & 6.9 \\
\hline
\end{tabular}

within-group variance in the vocabulary-oriented group. As could be expected, the two groups did not differ significantly from each other in their vocabulary size. Thus, possible performance differences between the two groups cannot be attributed to any differences in their vocabulary size, as measured by the Vocabulary Levels Test (Nation 2001).

5.3. Research question 1: What is the effect of treatment type on immediate and delayed word retention, as measured in a recall test?

As can be seen from Table 4, participants in the vocabulary-oriented group recalled the meaning of more words than participants in the message-oriented group in the immediate recall test. Though the difference was smaller on the delayed recall test, they still performed better than the message-oriented group.

All scores were submitted to an ANOVA with repeated measures, indicating that the differences in retention score were statistically significant (see Table 5). Moreover, its effect size was large $\left(\eta^{2}=.15\right)$. This means that the vocabularyoriented treatment resulted in better word retention compared to the messageoriented treatment.

Participants' test scores are also presented graphically in Figure 3. Vocabulary retention between the immediate and delayed tests dropped for both 
Table 4. Descriptive statistics of recall tests (Max $=14)$

\begin{tabular}{lcccccc}
\hline & $\mathrm{N}$ & \multicolumn{2}{c}{ Immediate recall test } & & \multicolumn{2}{c}{ Delayed recall test } \\
\cline { 3 - 4 } & & Mean & SD & & Mean & SD \\
\hline Message-oriented group & 29 & 5.45 & 2.9 & & 3.59 & 2.5 \\
Vocabulary-oriented group & 27 & 8.81 & 3.6 & & 5.15 & 3.8 \\
All students & 56 & 7.07 & 3.7 & & 4.34 & 3.3 \\
\hline
\end{tabular}

Table 5. ANOVA of recall tests

\begin{tabular}{lrrcc}
\hline & DF & $F$ value & $\operatorname{Pr}>F$ & $\eta^{2}$ \\
\hline Treatment (between-subject) & 1 & 169.81 & .004 & .15 \\
Time (within-subject) & 1 & 79.74 & $<.0001$ & .56 \\
Treatment*Time & 1 & 8.50 & .005 & .06 \\
Error & 54 & & & \\
\hline
\end{tabular}

groups, which is consistent with results in similar studies (Peters et al. 2009; Pulido 2007). The difference in retention score was statistically significant (= significant effect of Time). In addition, Table 5 shows that its effect size was very large $\left(\eta^{2}>.56\right)$.

As can be gleaned from Figure 3, the participants in the vocabulary-oriented group forgot more words than those in the message-oriented group, though it must be stressed that they still performed better. In other words, vocabulary loss was not the same in the two groups. The ANOVA demonstrated that the interaction between Treatment and Time was statistically significant. The effect size was moderate $\left(\eta^{2}=.06\right)$.

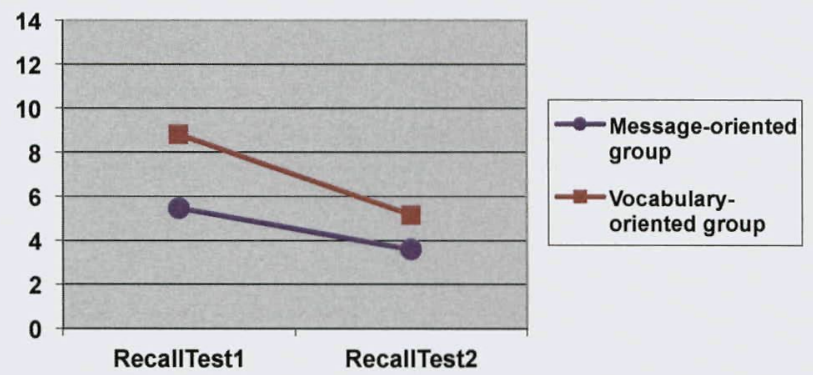

Figure 3. Graphic presentation of recall test scores 


\subsection{Research question 2: What is the effect of treatment type on immediate} and delayed word retention, as measured in a recognition test?

Both groups obtained higher scores on the recognition test than on the recall test immediately after the experimental task as well as two weeks later (see Table 6). The difference in score between the recall and recognition test was statistically significant, as indicated by a paired $t$-test $(t=-9.83 ; D F=55$; $p<.0001$ for the immediate post-tests; $t=-14.70 ; D F=55 ; p<.0001$ for the delayed post-tests).

The figures in Table 6 show that the vocabulary-oriented group performed better on the immediate and the delayed recognition test than the messageoriented group. An ANOVA with repeated measures (see Table 7) indicated that the differences in retention score between the two groups were statistically significant. Though these results corroborate the findings of the Recall test, the effect size was no longer large but moderate $\left(\eta^{2}=.10\right)$.

The results also showed that the test scores of both groups were lower on the delayed than on the immediate recognition test (see Figure 4), which is in line with other similar studies (Peters et al. 2009; Pulido 2007). The ANOVA showed that the effect of Time or the difference between the two tests was statistically significant (see Table 7). As can be gleaned from Figure 4, the two lines run quite parallel, which means that the number of words forgotten was about the same in the message-oriented as in the vocabulary-oriented group. Thus, unsurprisingly, the interaction between Treatment and Type was not significant (see Table 7).

To sum up, the findings showed that the vocabulary-oriented treatment yielded higher word retention scores than the message-oriented treatment on the immediate as well as delayed post-tests. Moreover, the difference was larger when the target words were tested in a recall test compared to a recognition test.

Table 6. Descriptive statistics of recognition tests (Max $=14$ )

\begin{tabular}{lcccccc}
\hline & $N$ & \multicolumn{2}{c}{ Immediate recognition test } & \multicolumn{2}{c}{$\begin{array}{c}\text { Delayed recognition } \\
\text { test }\end{array}$} \\
\cline { 3 - 4 } \cline { 7 - 8 } & & Mean & SD & & Mean & SD \\
\hline Message-oriented Group & 29 & 9.10 & 2.5 & & 8.38 & 3.1 \\
Vocabulary-oriented Group & 27 & 11.00 & 2.7 & & 9.81 & 3.2 \\
All students & 56 & 10.02 & 2.7 & & 9.07 & 3.2 \\
\hline
\end{tabular}


Table 7. ANOVA of recognition tests

\begin{tabular}{lrrcr}
\hline & DF & $F$ value & $P r>F$ & $\eta^{2}$ \\
\hline Treatment (between-subject) & 1 & 5.72 & .02 & .10 \\
Time (within-subject) & 1 & 8.24 & .006 & .13 \\
Treatment*Time & 1 & 0.48 & .49 & .01 \\
Error & 54 & & & \\
\hline
\end{tabular}

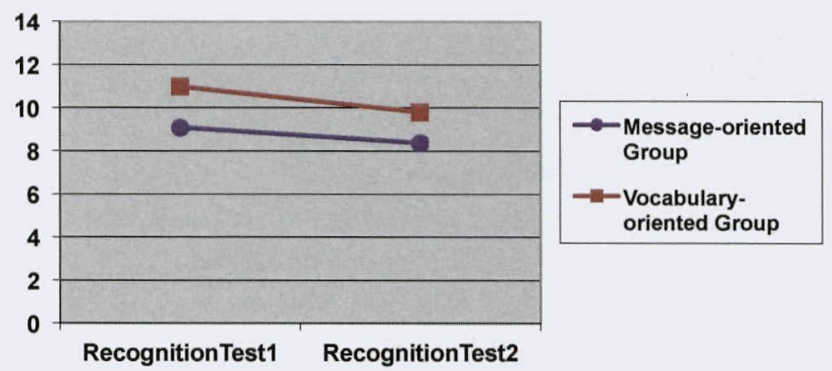

Figure 4. Graphic representation of recognition test scores

\subsection{Retrospective questions}

After the vocabulary post-tests, all participants answered three retrospective questions about how they had experienced their experimental task.

1. Had you expected vocabulary post-tests?

2. Do you think that the task you were set was a good preparation for the vocabulary post-tests?

3. Did you find the task motivating?

As can be seen in Table 8, the two groups did not differ much in their perception of the task. Most participants had not expected vocabulary post-tests, neither in the message-oriented group nor in the vocabulary-oriented group.

Table 8. Frequency table of retrospective questions

\begin{tabular}{|c|c|c|c|c|c|c|c|}
\hline & \multirow[t]{2}{*}{$N$} & \multicolumn{2}{|c|}{ Question 1} & \multicolumn{2}{|c|}{ Question 2} & \multicolumn{2}{|c|}{ Question ? } \\
\hline & & Yes & No & Yes & No & Yes & No \\
\hline Message-oriented group & 29 & 6 & 23 & 21 & 8 & 21 & 7 \\
\hline Vocabulary-oriented group & 27 & 7 & 20 & 26 & 1 & 17 & 9 \\
\hline
\end{tabular}


A large number of the learners in the message-oriented group thought that the text comprehension task was a good preparation for the post-tests. Except for one participant, all participants in the vocabulary-oriented group considered they were well prepared for the post-tests. In general, most learners enjoyed carrying out their task, though slightly more participants in the messageoriented group considered their task motivating compared to the vocabularyoriented group. Several students (in both groups) explicitly mentioned that this was because they found the topic of the text interesting.

\section{Discussion}

This study aimed to explore the effects of a message-oriented and a vocabularyoriented instruction treatment on meaning recall and meaning recognition of 14 target words. The findings obtained in this experiment indicate that the two groups learned a substantial number of words while engaging in their respective tasks but that the vocabulary-oriented group performed better on the immediate and delayed post-tests without needing more time to complete their tasks. Participants who were forced to pay attention to unfamiliar words in the reading text via comprehension questions (the message-oriented group) retained 39 to $65 \%$ of the target words dependent on the test, which is in line with the research findings obtained by Peters (2007). Participants in the vocabularyoriented group, on the other hand, retained 63 to $79 \%$ of the target words. This finding is comparable to the results in the studies by Hill and Laufer (2003) and Laufer (2006) but lower than the findings obtained in the study by Peters et al. (2009). In addition, the effect of treatment was larger when the target words were provided in a recall test in comparison to a recognition test, which implies that there were not only quantitative but also qualitative differences in word retention between the two groups. As a consequence, it can be said that, in terms of task-effectiveness, the vocabulary-oriented treatment was more effective than the meaning-oriented treatment because the former yielded higher learning gains without requiring more time.

The following factors may be ruled out as explanatory variables for the better learning performance of the vocabulary-oriented group. First, the results cannot be attributed to differences in vocabulary size between the two groups, as measured by the Vocabulary Levels Test. Second, participants in the vocabularyoriented group did not need more time to complete their task compared to participants in the message-oriented group. On the contrary, they were able to finish their task on average four minutes earlier. Finally, it is highly unlikely that learners' perception of the task contributed to the better retention scores because the two groups barely differed in how they had experienced the experimental treatment. The majority of learners had not expected vocabulary 
post-tests. Further, most learners found their task motivating to do. They also considered their task a good preparation for the vocabulary post-tests.

\subsection{Interpretation of results}

How can the better results of the vocabulary-oriented treatment be explained? What did the participants do while engaging in their task? In the remainder of this section, four possible explanations are provided: degree of guidance, time-on-target words, repetition, and the format of the post-tests.

Although the two treatments prompted learners to pay attention to and process the target words in the text, either via comprehension questions or via vocabulary tasks, they differed in their degree of guidance. The vocabularyoriented treatment consisted of two guided and well-focused vocabulary tasks. In these tasks, learners' attention was drawn directly to the target words. It was obvious that the aim of the task was to practise unfamiliar words. It was also obvious which words needed to be practised. Under the message-oriented treatment, learners' attention was also drawn to the target words but in an indirect way. Although the target words were essential to accomplish the task successfully in both treatments, the participants in the message-oriented group were not told explicitly which target words were relevant for the successful completion of their task. Hence, it cannot be ruled out that some students allocated their attention to words other than the target words. A comparison of the task scores shows that the mean scores of the vocabulary-oriented tasks were indeed higher than the mean score of the message-oriented task. To ascertain that this higher score was not the reason for the better performance of the vocabulary-oriented group, it was verified whether and how often a correct answer to the comprehension questions resulted in a correct test score. Remember that a correct answer in the comprehension task entails the integration of the target word's meaning in a meaningful proposition related to the comprehension question.

The analysis showed that the integration of a target word's meaning in the answer to the accompanying question, and thus a correct answer in the messageoriented task, did not automatically result in retention of the target word as measured in the vocabulary post-tests. A correct answer in the vocabulary tasks (= provision of a correct translation in the translation task and ticking off the correct meaning in the recognition task), on the other hand, resulted more often in retention of the target word. For instance, 27 of the 29 participants in the message-oriented group integrated the meaning of the target word adversity correctly in their answer to the pertaining question. Yet, only eight participants were able to supply its correct translation in the immediate recall test. Of the 26 students in the vocabulary-oriented group who provided a correct answer for 
adversity in both vocabulary tasks, 19 could supply the correct meaning in the immediate recall test. Similar results were found for most of the other target words. In other words, processing the target words by supplying their meaning in the vocabulary tasks was more likely to result in successful word retention than processing the target words by integrating the target words' meaning in an answer to the comprehension questions. Thus, the findings of the present study suggest that a direct approach to teaching new words is likely to result in greater word retention than an indirect approach.

Although most participants in the meaning-oriented group processed and integrated the target words' meaning in their answers, they did not learn as many target words as the vocabulary-oriented group, which may also be explained in terms of time spent on the target words. This could be a consequence of the direct approach to the target words in the vocabulary-oriented treatment. Though both groups needed approximately the same amount of time to complete their task, learners in the vocabulary-oriented group may have spent more time on the target words than the message-oriented group. Learners assigned to the latter group had to find the answer to comprehension questions in a reading text. First, they had to locate the answer in the text. Next, they had to verify whether the information was appropriate. Moreover, they had to formulate their answer in Dutch. Most questions did not require a single word but a phrase or sentence containing the target word's meaning. As a result, writing down the answers took some time as well. On the other hand, learners in the vocabularyoriented group devoted their time to finding or verifying the meaning of the target words, translating the task items and ticking off the correct meaning of the target words. For each item, the paragraph in which they could find the word was indicated. Hence, it is not unlikely that the vocabulary-oriented group devoted all or most of their time to the target words proper since their attention was drawn directly to the target words. Hill and Laufer (2003: 103) have also pointed out that it 'is not time spent on the task, but time spent on the target item' that is decisive.

A third possible explanation for the better performance of the vocabularyoriented group can be found in the multiple exposures to the target words. All learners encountered the words when reading the text (= first encounter). Learners in the message-oriented group probably established the form-meaning connection of (some of) the target words while answering the comprehension questions, whereas learners in the vocabulary-oriented group did so during the first vocabulary task (= the translation task) (= second encounter). In addition, the latter group processed the target words again during the second vocabulary task, multiple-choice task (= third encounter). Thus, they encountered the target words at least three times. This means that the second vocabulary task could be considered a repetition task. Nation (2001: 67) states that the form-meaning link of a word will be strengthened if that word is subsequently retrieved dur- 
ing a task. In other words, the route connecting the meaning and form was reinforced during the second vocabulary task because it allowed the learners to consolidate their knowledge of the target words. Nation emphasizes that "it is not simply repetition which is important but the repeated opportunity to retrieve the item which is to be learned" (2001: 67). Similarly, Folse (2006) argued that the number of word retrievals is even more important than depth of word processing. With regard to the effect of repetition, the present research findings are consistent with the study by Peters et al. (2009). Both studies indicate that repetition can bring about a significant increase in vocabulary learning gains.

Nevertheless, it cannot be ruled out that the participants in the vocabularyoriented treatment benefited from the format of the post-tests. The two posttests as well as the two vocabulary tasks presented the target words as discrete items. Although the post-tests were not identical to the tasks, the task-test similarity was greater for the vocabulary-oriented group than for the messageoriented group. Participants in the vocabulary-oriented group had already worked with the target words in terms of supplying translations and ticking off (L2) synonyms. As a result, the format of the post-tests may have favored this group to some extent.

The findings obtained in this study seem to have implications for teaching because recall of the target words' meaning, as measured by the two post-tests, was better in the vocabulary-oriented group compared to the message-oriented group. First, a direct approach to learning the meaning of new words may promote the salience of target words (in a text) more effectively than an indirect approach. This is especially relevant when low-frequency words are concerned. The findings presented here suggest that a direct approach could be an effective way to draw attention to these words. In terms of task-effectiveness, a direct and vocabulary-oriented approach seems to be a faster way to learn new vocabulary as well, which is an important consideration, given time-constraints in many foreign language learning contexts. Third, the importance of multiple encounters with new words should be underscored. More opportunities for retrieval allow learners to consolidate the form-meaning connections of words previously encountered in a reading text (Hulstijn 2001; Laufer 2005; Nation 2001). The claim for (more) vocabulary-oriented activities or form-focused instruction and repetition opportunities in vocabulary instruction is not a new one (Laufer 2005; Nation 2001; Schmitt 2008). Researchers, such as Hulstijn, Laufer, Nation, and Schmitt to name just a few, have repeatedly advocated the use of direct vocabulary teaching in addition to reading activities. This study adds to the growing body of evidence underlying this claim, though it needs to be emphasized that a direct vocabulary approach is not the only pedagogic avenue for successful vocabulary teaching.

It needs to be acknowledged, however, that this study reports only on measured gains (= recall of the target words' meaning) and not on unmeasured 
gains, resulting from students' engagement with other lexical items. Nevertheless, it seems that, in terms of task-effectiveness, the vocabulary-oriented treatment is likely to be more effective than the message-oriented treatment because it resulted in better word retention (quantitatively and qualitatively) without requiring more time.

\section{Conclusion}

This study aimed to explore the effects of a message-oriented treatment (= reading text + text comprehension task) and a vocabulary-oriented treatment (= reading text + two vocabulary tasks) on EFL learners' retention of 14 target words. Learners in both treatments first read a text in which they encountered the unfamiliar target words for the first time. All learners were required to use the target words in either the message-oriented or the vocabulary-oriented task (i.e. the target words were essential to both tasks), and all learners were allotted the same amount of time. The findings indicate that both treatments yielded vocabulary gains but that the vocabulary-oriented treatment resulted in higher word retention than the message-oriented one in the immediate as well as in the delayed vocabulary post-tests. In other words, in terms of taskeffectiveness, the vocabulary-oriented treatment was more effective than the message-oriented treatment without requiring more time. The reason for the better learning performance in the vocabulary-oriented treatment may be attributed to the degree of guidance, i.e. attention drawn to the target words (direct versus indirect), the time-on-target words, and the repeated opportunities for retrieval.

Acknowledgements. I would like to thank my colleague Paul Pauwels for his help in the data collection. I am also grateful to the reviewers' and editor's valuable comments and suggestions.

KU Leuven, University of Leuven, and Lessius Antwerpen 〈elke.peters@arts.kuleuven.be〉

\section{References}

Alderson, J. Charles. 2000. Assessing reading. Cambridge: Cambridge University Press.

Chun, Dorothy \& Jan L. Plass. 1996. Effects of multimedia annotations on vocabulary acquisition. The Modern Language Journal 80. 183-198.

Cohen, Jacob. 1992. A power primer. Psychological Bulletin 112. 155-159.

Craik, Fergus I. M. \& Robert S. Lockhart. 1972. Levels of processing: A framework for memory research. Journal of Verbal Learning and Verbal Behavior 11. 671-684. 
Craik, Fergus I. M. \& Endel Tulving. 1975. Depth of processing and the retention of words in episodic memory. Journal of Experimental Psychology: General 104. 268-294.

De Ridder, Isabelle. 2002. Visible or invisible links: Does the highlighting of hyperlinks affect incidental vocabulary learning, text comprehension and the reading process? Language Learning \& Technology 6. 123-146. Retrieved January 21, 2003 from http://lt.msu.edu/vol6num1/ deridder/default.html.

Ellis, Rod. 2003. Task-based language learning and teaching. Oxford: Oxford University Press.

Folse, Keith S. 2006. The effect of type of written exercise on L2 vocabulary retention. TESOL Quarterly 40(2). 273-293.

Garcia-Mayo, Maria del Pilar. 2006. Investigating tasks in formal language learning. Clevedon: Multilingual Matters

Hill, Monica \& Batia Laufer. 2003. Type of task, time-on-task and electronic dictionaries in incidental vocabulary acquisition. IRAL 41. 87-106.

Horst, Marlise, Tom Cobb, \& Paul Meara. 1998. Beyond a clockwork orange: acquiring second language vocabulary through reading. Reading in a Foreign Language 11. 207-223.

Hulstijn, Jan H. 2001. Intentional and incidental second language vocabulary learning: a reappraisal of elaboration, rehearsal and automaticity. In Peter Robinson (ed.), Cognition and second language instruction, 258-286. Cambridge: Cambridge University Press.

Hulstijn, Jan H., Merel Hollander \& Tine Greidanus. 1996. Incidental vocabulary learning by advanced foreign language students: the influence of marginal glosses, dictionary use, and reoccurrence of unknown words. The Modern Language Journal 80. 327-339.

Hulstijn, Jan H. \& Batia Laufer. 2001. Some empirical evidence for the involvement load hypothesis in vocabulary acquisition. Language Learning 51. 539-558.

Laufer, Batia. 2005. Focus on Form in second language vocabulary learning. In Susan H. FosterCohen, Maria del Pilar Garcia-Mayo \& Jasone Cenoz (eds.), Eurosla yearbook, Volume 5, 223-250. Amsterdam/Philadelphia: John Benjamins Publishing Company.

Laufer, Batia. 2006. Comparing Focus on Form and Focus on FormS in second language vocabulary learning. The Canadian Modern Language Review 63. 149-166.

Laufer, Batia \& Monica Hill. 2000. What lexical information do L2 learners select in a CALL dictionary and how does it affect word retention? Language Learning \& Technology 3. 58-76. Retrieved October 29, 2002 from http://ltt.msu.edu/vol3num2/laufer-hill/index.html

Laufer, Batia \& Bella Rozovski-Roitblat. 2011. Incidental vocabulary acquisition: The effects of task type, word occurrence and their combination. Language Teaching Research 15(4), 391411.

Long, Michael. 1991. Focus on Form: a design feature in language teaching methodology. In K. de Bot, R. Ginsberg, and C. Kramsh (eds.), Foreign language research in cross-cultural perspective, 39-52, Amsterdam: John Benjamins.

Loschky, Lester \& Robert Bley-Vroman. 1993. Grammar and task-based methodology. In G. Crookes \& S. M. Gass (eds.), Task and language learning: Integrating theory and practice, 123-167. Clevedon: Multilingual Matters.

Mondria, Jan-Arjen. 2003. The effects of inferring, verifying and memorizing on the retention of L2 word meanings: an experimental comparison of the "meaning-inferred method" and the "meaning-given method". Studies in Second Language Acquisition 25. 473-500.

Mondria, Jan-Arjen \& Boukje Wiersma. 2004. Receptive, productive, and receptive + productive L2 vocabulary learning. What difference does it make? In Paul Bogaards, \& Batia Laufer (eds.), Vocabulary in a Second Language, 79-100. Amsterdam/Philadelphia: John Benjamins.

Nation, Paul. 2001. Learning vocabulary in another language. Cambridge: Cambridge University Press.

Paribakht, T. Sima \& Marjorie Wesche. 1997. Vocabulary enhancement activities and reading for meaning in second language vocabulary acquisition. In James Coady \& Thomas Huckin (eds.),Second language vocabulary acquisition. A rationale for pedagogy, 174-200. Cambridge: Cambridge University Press. 
Paribakth, T. Sima \& Marjorie Wesche. 1998. "Incidental" and instructed L2 vocabulary acquisition: Different contexts, common processes. In Dorte Albrechtsen, Birgit Henriksen, Inger Mees, and Erik Poulsen (eds.), Perspectives on foreign and second language pedagogy. Essays presented to Kirsten Haastrup on the occasion of her sixtieth birthday, 203-220. Odense: Odense University Press.

Peters, Elke. 2007. Manipulating L2 learners' online dictionary use and its effect on L2 word retention. Language Learning \& Technology 11. 36-58. Retrieved July 1, 2007, from http:// llt.msu.edu/vol11 num2/peters/default.html

Peters, Elke, Jan H. Hulstijn, Lies Sercu, \& Madeline Lutjeharms. 2009. Learning L2 German vocabulary through reading: the effect of three enhancement techniques compared. Language Learning 59. 113-151.

Pulido, Diana. 2007. The effects of topic familiarity and passage sight vocabulary on L2 lexical inferencing and retention through reading. Applied Linguistics 28. 66-86.

Richards, Jack, John Platt, \& Heidi Weber. 1985. Longman dictionary of applied linguistics. Harlow: Longman.

Schmitt, Norbert. 2008. Review article. Instructed second language vocabulary learning. Language Teaching Research 12. 329-363

Sinclair, John (ed.). 2001. Collins cobuild English dictionary for advanced learners. Glasgow: Harper Collins Publishers

Skehan, Peter. 1998. A cognitive approach to language learning. Oxford: Oxford University Press

Steinel, Margarita P. , Jan H. Hulstijn, \& Wolfgang Steinel. 2007. Second language idiom learning in a paired-associate paradigm: effects of direction of learning, direction of testing, idiom imageability, and idiom transparency. Studies in Second Language Acquisition 29. 449-484.

Van den Branden, Kris. 2006. Task-based language education: From theory to practice. Cambridge: Cambridge University Press.

Van den Branden, Kris, Martin Bygate \& John Norris (eds.). 2009. Task-based language teaching. A reader. Amsterdam/Philadelphia: John Benjamins Publishing Company. 
Copyright of IRAL: International Review of Applied Linguistics in Language Teaching is the property of De Gruyter and its content may not be copied or emailed to multiple sites or posted to a listserv without the copyright holder's express written permission. However, users may print, download, or email articles for individual use. 